\title{
Autosomal dominant spastic paraplegia type 37
}

INSERM

\section{Source}

INSERM. (1999). Orphanet: an online rare disease and orphan drug data base. Autosomal dominant spastic paraplegia type 37. ORPHA:171612

Autosomal dominant spastic paraplegia type 37 is a pure form of hereditary spastic paraplegia characterized by a childhood- to adulthood-onset of slowly progressive spastic gait, extensor plantar responses, brisk tendon reflexes in arms and legs, decreased vibration sense at ankles and urinary dysfunction. Ankle clonus is also reported in some patients. 